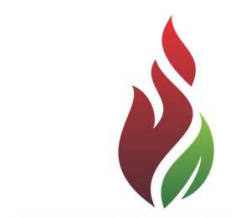

SUSTENERE

Publishing Corporation

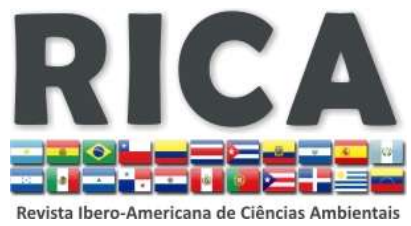

Journals Homepage:

www.sustenere.co/journals

\section{A CULTURA DO CONSUMISMO: CONSCIÊNCIA E SUSTENTABILIDADE COMO VALORES ABSTRATOS}

\section{RESUMO}

O objetivo deste artigo foi refletir sobre o comportamento orientado para um consumo consciente e sustentável. Para tanto, utilizou-se uma abordagem interpretativista, interdisciplinar e sistêmica de forma que abrangesse questões relacionadas à economia, cultura, produção, entre outras. A discussão das ideias apresentadas neste trabalho partiu do pressuposto de que só se pode construir um consumo consciente se for entendido os fatores culturais relacionados ao comportamento do consumidor. No Brasil, a influência do consumo destaca um comportamento orientado pelo valor de bens e serviços, com parte das escolhas suprindo necessidades e desejos orientados por uma visão hedonista e inconsciente. Embora esta seja uma realidade compartilhada entre a maioria dos consumidores brasileiros, vale lembrar que a produção e o consumo geram externalidades negativas que, em algum momento, serão internalizadas. Assim, o consumo sustentável pode ser adotado de forma consciente ou por imposição das situações ambientais como no caso da água na região sudeste do Brasil em 2014.

PALAVRAS-CHAVES: Comportamento do Consumidor; Sustentabilidade; Consumo Consciente.

\section{THE CULTURE CONSUMERISM: AWARENESS AND SUSTAINABILITY AS VALUES ABSTRACT}

\section{ABSTRACT}

The purpose of this article was to reflect on the behavior oriented conscious and sustainable consumption. Therefore, we used an interpretative approach, interdisciplinary and systemic way of covering issues related to the economy, culture, production, among others. The discussion of the ideas presented in this paper started from the assumption that one can only build a conscious consumption if it is understood the cultural factors related to consumer behavior. In Brazil, the influence of consumption highlights a behavior guided by the value of goods and services, with some of the choices providing necessities and desires guided by a hedonistic and unconscious vision. Although this is a shared reality among the majority of Brazilian consumers, it is worth remembering that the production and consumption generate negative externalities that, at some point, be internalized. Thus, sustainable consumption can be adopted consciously or imposition of environmental situations as in the case of water in southeastern Brazil in 2014.

KEYWORDS: Consumer Behavior; Sustainability; Conscious Consumption.
Revista Ibero-Americana de

Ciências Ambientais, Aquidabã, v.6, n.1, Dez2014, Jan, Fev, Mar, Abr, Mai 2015.

ISSN 2179-6858

SECTION: Articles

TOPIC: Consumo e Meio Ambiente

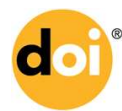

DOI: 10.6008/SPC2179-6858.2015.001.0002

Luciano Ferreira da Silva

Pontifícia Universidade Católica, Brasil http://lattes.cnpq.br/3790925273077368 If silvabr@yahoo.com.br

Leonardo Nelmi Trevisan

Pontifícia Universidade Católica, Brasil http://lattes.cnpq.br/6128983828748446 Intrevisan@pucsp.br

Arnoldo José de Hoyos Guevara Pontifícia Universidade Católica, Brasil http://lattes.cnpq.br/1249843121429282 arnoldodehoyos@yahoo.com.br

Received: 01/12/2014

Approved: 09/04/2015

Reviewed anonymously in the process of blind peer

\section{Referencingthis:}

SILVA, L. F.; TREVISAN, L. N.; GUEVARA, A. J. H.. A cultura do consumismo: consciência e sustentabilidade como valores abstratos. Revista Ibero-Americana de Ciências Ambientais, Aquidabã, v.6, n.1, p.14-22, 2015. DOI: $\underline{\text { http: } / / d x . d o i . o r g / 10.6008 / S P C 2179-}$ $\underline{6858.2015 .001 .0002}$ 


\section{INTRODUÇÃO}

O consumo pode ser percebido como um processo social estabelecido para satisfazer os desejos e as necessidades de um indivíduo com a livre criação e oferta de bens e serviços por organizações (KOTLER \& KELLER, 2006). Nesta relação entre indivíduos e empresas, aparentemente em mercados livres e desenvolvidos, as pessoas possuem liberdade para escolher suas compras de acordo com suas crenças e valores, que serão utilizadas nas avaliações destes bens e serviços. Não obstante, a situação supracitada leva a discutir a relação entre a consciência e o consumo de bens e serviços, o que proporciona à oportunidade de refletir sobre os processos sociais que são sujeitos à influência de uma relação entre os anseios dos indivíduos e os benefícios ou malefícios causados ao coletivo oriundos do consumo.

A relação entre consumo como um processo social que passa por escolhas entre desejos e necessidades está relacionada à ideia de Perelman (2000) sobre a relação do orador com o auditório. $O$ autor sugere que a pretensão do acordo universal pode ser considerada válida para auditórios universais. Assim, ao estabelecer este vínculo inicial é possível inserir diversos públicos na discussão a que se propõe este ensaio. Deste modo, o consumo como um acordo universal e naturalizado faz com que a individualidade prevaleça ante os anseios coletivos. Sendo assim, as necessidades e desejos individuais são valorados acima dos prejuízos que podem surgir do processo de consumo. Contudo, um novo elemento deve ser inserido nesta discussão que é o conceito de sustentabilidade.

Para os estudos sobre sustentabilidade se faz necessário entender os fluxos entre os agentes econômicos. Aliás, vale destacar que a perspectiva macroeconômica determina que as limitações apontadas na quantificação dos bens ambientais reproduzem-se e ampliam-se fortemente, isto ocorre por que o contexto envolve grandes agregados macroeconômicos (MATOS et al., 2011; BECK, 2010). Portanto, a posse e a transformação de recursos naturais, como o uso de matérias-primas no processo de produção, favorecem o desperdício e pode levar a privação de recursos para a atividade humana futura. Este raciocínio, sobre a utilização inconsequente dos recursos para a produção de bens e serviços, pode ser compreendido na forma como as instituições públicas e privadas exploram os recursos em progressão infinitamente superior à capacidade de regeneração do planeta (LEITE \& SILVA, 2012). Esta situação, a produção e consumo de forma inconsciente e inconsequente, cria uma lógica futura perversa para todos. Isto se dá por que esta condição poderá gerar um passivo socioambiental por conta de decisões como a de substituir pessoas com base em uma política de diminuição dos custos, ou ainda pela extração e utilização dos recursos naturais realizadas por uma visão hedonista de curto prazo.

Assim, ao inserir a sustentabilidade nas suas dimensões sociais, ambientais e econômicas na discussão sobre o consumo estabelece-se um viés para a argumentação deste ensaio. Como salienta Perelman (2000) ao atribuir uma hierarquia de valor à discussão é possível dar significado ao conteúdo e, consequentemente, estabelecer um contrato intelectual sobre o processo comunicativo entre o orador e o auditório neste texto. Portanto, a ideia que segue neste artigo é a 
de que o consumo, enquanto ação, passa pela reflexão individual. E, valores e crenças implícitos nesta reflexão, intervêm na retórica do consumo. Outro ponto que deve ser destacado quando na discussão do conceito de sustentabilidade sobre consumo, além da sua delimitação, é a justificativa ou relevância deste debate. Como descreve Perelman (2000, p.85), "numa discussão, não podemos subtrair-nos ao valor negando-o pura e simplesmente [...]", caso contrário não poderia ser entendido como discussão, mas sim como o domínio da força. Portanto, a sustentabilidade aqui é entendida como um valor abstrato que se apresenta relevante para discussão, pois não é uma realidade absoluta e indiscutível (PERELMAN, 2000). Deste modo, justifica-se o estudo para a construção de saberes ou valores que contribuam para o aprimoramento da argumentação e retórica neste tema, imbuídos do processo lógico e dialético (ARIDA, 2003).

\section{DISCUSSÃO TEÓRICA}

\section{A Cultura do Consumismo: do Consumismo ao Consumo Consciente}

A discussão quanto ao consumo tratado neste trabalho representa uma relação entre valores pessoais e coletivos que orientam às ações que causam efeitos ao meio ambiente. Esta é uma relação visível quando se propõe tratar do consumo e da sustentabilidade, principalmente, quando o foco é abordar as crenças e valores individuais e a mudança destes por fatores ambientais e coletivos. Para que a discussão proposta possa apresentar a realidade do indivíduo, ou sua subjetividade, em seu papel de consumidor é preciso compreender as questões culturais inseridas neste papel. Não obstante, vale destacar que este trabalho parte da ideia de sustentabilidade como um valor abstrato, pois não é uma realidade absoluta e indiscutível para os consumidores (PERELMAN, 2000).

Portanto, ao entender os aspectos relacionados à cultura, que influenciam o comportamento dos indivíduos, cria-se um contexto para a construção de argumentos reais sobre os valores inseridos nos papéis de consumidor e de cidadão. Assim, a cultura dos indivíduos pode explicar o comportamento analisado. A cultura pode ser definida como "[...] um padrão de suposições básicas compartilhadas, que foi aprendido por um grupo à medida que solucionava seus problemas de adaptação externa e de integração interna (SCHEIN, 2009, p.16)". Assim, pode ser inferido que a relação de consumo somente pelo consumo representa a suposição básica, ou como descreveu Perelman (2000) um valor concreto. Deste modo, ao tratar a relação indivisível entre o consumo e a sustentabilidade, compreende-se que o primeiro gera externalidades negativas que impactam no segundo, sendo que é o próprio indivíduo que vai arcar com este ônus. Embora uma visão prática desta relação possa ser demonstrada, não é possível quebrar facilmente a suposição básica construída como valor concreto para um individualismo no comportamento de consumo. 
Um retrato da evolução do consumo no Brasil pode explicar estes valores tão fortes de consumir sem se preocupar com os efeitos desta ação. Para tanto, deve ser traçado uma linha de tempo do que é consumir no Brasil, o que possibilitará depreender que a liberdade para consumir foi adquirida nas últimas duas ou três décadas. Destaca-se que o indivíduo no Brasil viveu até praticamente a década de 1990 uma reserva de mercado, além de passar por uma década que ficou conhecida como uma década perdida (1980), cuja geração de emprego e renda quase não acontecia. A inflação neste período se tornou um fator que estava assolando o país, as taxas de $30 \%$ da década de 1970, chagaram à 100\% em 1980. Em 1983 passam à 200\% e chegam a 400\% em 1987 (BRESSER PEREIRA, 2003; TEIXEIRA \& TOTINI, 1989). Deste modo, a realidade de consumo no Brasil, construída com base em um mercado extremamente fechado e uma inflação que retirava o poder de compra, levou a um comportamento de consumo de sobrevivência. O comportamento de compra se dava por uma questão da acessibilidade aos produtos e a quantia de dinheiro disponível. Esta situação instituiu um valor pessoal de consumo pelo acesso, o que pode explicar a cultura do consumismo, pois o maior poder de compra e o acesso mais fácil a bens e serviços levaram automaticamente a consumir mais. Então, pode se dizer que de forma generalizada o consumidor no Brasil está preocupado em suprir suas necessidades e desejos presentes. Sendo que este comportamento se torna uma suposição básica, o que se entendida, pode auxiliar na discussão de um consumo mais consciente. Deste modo, entender como se construiu a cultura de consumismo no Brasil auxilia a compreender como o consumo consciente pode ser construído.

\section{O Consumo Consciente}

Para iniciar esta discussão é relevante introduzir o problema criado entre privilegiar o econômico em detrimento do socioambiental, o que pode ser exemplificado pelo uso de um recurso de alto valor como uma árvore quando utilizada como madeira. O que é relevante na avaliação deste recurso é que o valor de mercado da madeira, na maioria das vezes, não leva em conta o custo socioambiental à sociedade por esta árvore ser cortada. O mesmo ocorre para o preço de um litro de gasolina ou a água potável fornecida às residências, pois seus custos não incluem a mudança climática ou a poluição local (BROWN, 2003).

Além do mais, vale destacar que a utilização dos recursos, sendo eles naturais ou não, nem sempre levam em conta as condições futuras de sua utilização. Esta situação leva às perdas que ocorrem em grande escala e se acumulam a outros fatores sociais. De outro lado, uma escassez ecológica que afeta a água e os alimentos pode criar riscos econômicos, sociais e ambientais que serão sentidos por todos. Para tanto, se faz necessário entender de forma sistêmica o ambiente em que as organizações estão inseridas ou mesmo o local de onde retiram os seus recursos, pois a forma com que elas operarão poderá ameaçar a própria sobrevivência do sistema global do planeta terra (SUKHDEV, 2013). Não obstante, para compreender estas ameaças também é preciso entender o que são as externalidades. 
As externalidades são representadas pelo custo ou benefício que um agente, na realização de uma atividade econômica, impõe a terceiros, sendo que isto pode acontecer de forma positiva ou negativa. Como exemplo de externalidade pode-se citar o pagamento de salários ou a formação de preços dos produtos, pois estas ações podem comprometer a renda ou bem-estar de outro agente econômico sem uma correspondente compensação (COELHO, 2012; GONÇALVES \& RIBEIRO 2013; OECD, 2011; CRUVINEL et al., 2012). Essa situação faz com que as instituições repensem suas ações, pois o meio ambiente é por sua natureza de direito difuso e de responsabilidade de todos os atores da sociedade. Isto ocorrendo no âmbito local ou global. Assim, as externalidades provenientes das ações de um agente têm repercussão de forma sistêmica em toda a natureza interconectada (ELTZ, 2012; COELHO, 2012).

Deste modo, os indivíduos, as empresas e os governos deveriam estar menos preocupados com as condições presentes da economia, ou somente com o fator econômico da sustentabilidade. Sendo que o foco deveria ser a preocupação com a capacidade futura de abrigar a vida na terra, tanto nas questões relacionadas à dimensão social, quanto à dimensão ambiental (MORIN, 2013; HENDERSON, 1991; 2003). Assim, a produção e o consumo de bens e serviços sem um viés de consciência sobre o futuro nestes aspectos citados pode comprometer esta própria relação e a sobrevivência das pessoas. Um exemplo sobre as condições futuras de forma sustentável e o consumo está no fornecimento de água em 2014 no estado de São Paulo, o que também já afeta quase toda a região sudeste do país $(G 1,2014)$. Neste ano devido a estiagem e a falta de controle ou gestão, a empresa responsável pelo fornecimento de água no Estado de São Paulo (Sabesp) já está usando a segunda parte do volume morto, ou seja, uma reserva técnica que não era computada na reserva oficial do sistema Cantareira.

Vale destacar que mesmo com a utilização da segunda parte da reserva técnica do sistema Cantareira, o seu nível está em 10,2\%, em meados de novembro de 2014. Essa situação faz com que diversas decisões de fornecimento e consumo deste bem sejam tomadas de forma distinta da que normalmente ocorreriam. Aliás, pode ser evidenciada uma "enxurrada", mas não de água e sim de comunicações para que ocorra um consumo consciente com relação à água surgindo de diversas partes da sociedade brasileira - empresas, cidadãos, Estado etc. Portanto, o consumo sem consciência ou a má gestão dos recursos hídricos pode fazer com que todos sofram já no presente. Além disso, se for utilizada uma abordagem mais abrangente e sistêmica para a avaliação do consumo e gestão dos recursos hídricos no Brasil, pode ser empregado o que ressalta o pesquisador Antônio Nobre, do Centro de Ciência do Sistema Terrestre (CCST), após analisar mais de 200 artigos científicos sobre a Amazônia. Nobre diz que a situação do clima com relação às chuvas no Brasil decorre do desmatamento da região Amazônica que está influenciando a falta de água nas regiões mais populosas do país.

Como destacado anteriormente, o corte de árvores não levam em conta os custos ambientais que são gerados desta ação. Assim, as externalidades negativas serão direcionadas para outros atores da sociedade, que somente conseguirão compreender esta relação entre consumo e consequência, se adotar uma visão mais aberta e sistêmica com relação à produção e 
o consumo. A tomada de consciência sobre esta realidade gera um estado socioecológico globalmente desejável, pois uma parte significativa do desafio de um futuro sustentável vem de tornar os serviços da biosfera visíveis na mente das pessoas, nas transações econômicas e financeiras, e na sociedade como um todo (HAWKEN et al., 2002; MORIN, 2013; HENDERSON, 1991; HENDERSON, 2003).

Portanto, quando inseridos os problemas socioambientais na discussão sobre o consumo, assunto este que foi por muitos anos uma preocupação apenas para o Estado e os ambientalistas, se deseja tratar a ação de consumo como algo mais complexo que não acaba em si mesma. Vale destacar que esse tema já vem sendo intensamente debatido por diversos autores que criticam as práticas tradicionais de consumo, justificando que o aumento da oferta e da produção não está alinhado com os problemas sociais e ambientais do planeta (HENDERSON, 1991; HENDERSON, 2003; ASSADOURIAN, 2013; SEN, 2000; BECK, 2011). Deste modo, a proposta de rever práticas de consumo abre espaço para novos conceitos como 'consumo verde', 'consumo sustentável' ou 'consumo consciente' (FABI et al., 2010; HAWKEN et al., 2002). Vale destacar que esta não é somente uma questão de semântica, pois impõe aos indivíduos uma forma de ver o ato de consumir não como atividade somente do presente, mas numa atividade que interferirá no seu consumo futuro. Portanto, a ação de produção e consumo deve levar em conta as externalidades negativas geradas. Assim, o consumidor e a sociedade ganham em longo prazo com um consumo mais consciente. Caso contrário, aumenta-se a probabilidade de que os recursos, principalmente os naturais, se tornem cada vez mais escassos e caros (ENGELMAN, 2013; HAWKEN \& LOVINS; LOVINS, 2002; MORIN, 2013).

Por outro, quando não há uma relação consciente entre a produção e o consumo, as unidades produtoras utilizam práticas para construir vantagens competitivas com base no controle dos recursos (NUNES et al., 2008). Como descrito já em Adam Smith em seu livro 'A Riqueza das Nações', bastava racionalizar os processos como na produção da fabrica de alfinetes (CASSIDY, 2011). Sendo que este controle levava a criação de valor para alguns bens e serviços pela visão de organização como agregados de recursos, que criam vantagens baseadas nas suas capacidades internas que são difíceis de copiar (NUNES et al., 2008). Além disso, a visão de gestão baseada no controle dos recursos permite compreender como algumas empresas construíam vantagens a partir de atributos físicos e financeiros, bem como nos intangíveis como marca, credibilidade ou tradição. Neste tipo de processo o valor estava baseado no senso de utilidade ou de troca (BRITO \& BRITO, 2012). Contudo, a visão que se apresenta de forma emergencial a preocupação com a escassez presente dos recursos, faz com que as unidades produtoras e consumidores adotem a escassez do bem natural ou condição social em seu processo de consumo.

Deste modo, a realidade apresentada neste início do século XXI impõe uma visão em que todos os custos e benefícios sociais e ecológicos, internos e externos, devam ser tanto quanto possíveis identificados e internalizados no processo de produção e consumo (HAWKEN et al., 2002). Esta internalização pode ocorrer pela assimilação dos custos presentes e futuros das 
externalidade no preço dos bens e serviços. Esta mudança de foco na economia faz com que a luta pela escassez requeira um esforço social abrangente para conservar os estoques remanescentes dos recursos naturais, além de tornar o seu uso mais consciente e inteligente. Nesta realidade, o grande desafio é aumentar consideravelmente a produtividade fazendo o menor uso possível dos recursos não renováveis (MOORE \& REES, 2013).

Segundo dados do Instituto Akatu o consumo humano já supera em $25 \%$ a capacidade de renovação dos recursos naturais no planeta e, se não forem alterados os atuais padrões de produção e consumo, em menos de 50 anos serão necessários dois planetas Terra para atender as demandas por água, energia e alimento. Assim, a vida no planeta pode ser dificultada por essa situação e a única forma de alterá-la é através de mudanças nos padrões de consumo (AKATU, 2008). Como salienta Bauman (2001), o consumismo é algo que não diz mais respeito somente a satisfação das necessidades. Por outro lado, o elemento motivador da atividade consumista não é mais um conjunto mensurável de necessidades articuladas naturalmente. $O$ autor ainda descreve que este ato é cada vez mais o desejo como uma entidade muito mais volátil e efêmera, além de evasiva e caprichosa.

Todavia, o consumo consciente quebra com este círculo vicioso que prejudica todos os envolvidos no processo. Assim, o foco no crescimento do consumo e, consequentemente, da produção, é substituído pela lógica do desenvolvimento sustentável da sociedade. A saída para o jogo perverso do consumismo está, ao menos em um dos seus elos, na mudança do comportamento dos consumidores. (HENDERSON, 2003; MORIN, 2013). Ramalho (2011) descreve que o estudo do consumo sustentável deve levar em conta três dimensões que são o caráter simbólico, cultural e político das relações de consumo. Silva et al. ( 2013) destaca que para mudar o comportamento de consumo deve-se levar a conscientização como um fator essencial para transformar os padrões de produção e consumo vigentes. Assim, para que uma nova visão possa emergir é necessário que haja um processo de mudança na responsabilidade tanto de produtores quanto de consumidores (DOWBOR, 2013).

Contudo, a mudança no comportamento dos indivíduos não pode ser influenciada somente quando da ocorrência de problemas como o da água na região sudeste. Mudar o comportamento quando o problema já é emergencial pode levar a outros problemas, pois como fazer como fazer para gerenciar a produção e o consumo de produto que já está em um estado avançado de escassez. Embora esta situação faça com que seja influenciada a subjetividade dos indivíduos, que por sua vez influencia as crenças e valores que alteram as suposições básicas com relação ao consumo. Além disso, de forma mais sistêmica pode-se dizer que a mudança nos padrões de consumo pode alterar a forma de produção de bens e serviços.

Conforme destacado por Harrison (2005) o papel do consumidor deve ser visto como um indutor do comportamento ético das empresas, além de ser, ele mesmo, consumidor, também é um ator a ser transformado, passando de um paradigma individualista para uma visão mais ética e coletivista sobre seu próprio papel na sociedade. Robinson (2004), diz que a sustentabilidade é uma questão de comportamento humano e negociação acerca do futuro, em condições de 
contingências profundas e incertas, como no caso da água. Assim, para que ocorra efetivamente um consumo mais sustentável é imprescindível um papel mais ativo do Governo, uma responsabilidade socioambiental das empresas, uma maior consciência individual, além do posicionamento de outros atores sociais envolvidos neste processo (PNUMA, 2014; SILVA, 2012; HENDERSON, 1996).

\section{CONCLUSÕES}

Ao delimitar o assunto pelo viés da sustentabilidade, com um olhar para as externalidades causadas pelo consumo, percebe-se a importância de entender que estes conceitos não são verdades absolutas. Portanto, pode ser justificada a relevância desta discussão pelas mudanças identificadas neste início do século XXI. Uma questão apresentada neste ensaio foi a da água na região sudeste, sendo esta uma situação que influencia a todos na sociedade, principalmente por ser este um bem necessário à própria condição de sobrevivência. Vale destacar que a construção de uma atitude voltada para o consumo consciente e sustentável passa pela mudança em suposições básicas, ou seja, valores e crenças que constituem a cultura dos indivíduos. Assim, como descrito anteriormente para tentar mudar a cultura do consumismo deve-se compreender como a mesma foi construída. No caso brasileiro pelo cenário de privações no consumo oriundas de reserva de mercado e inflação que retirava o poder de compra.

Em resumo, pode-se dizer que o pensamento defendido aqui é de que o consumo consciente e responsável não é uma escolha. Aliás, a exploração dos recursos de forma inconsciente e inconsequente levará a um comportamento de produção e consumo conscientes e sustentáveis no futuro. Exatamente como o que foi exposto no caso da água em São Paulo. Portanto, o caminho para o consumo sustentável pode vir por vias de consciência ou pela coerção imposta pelo ambiente quando este demanda ações para seus problemas. Estes problemas podem surgir de questões sociais, como pobreza, doenças e carências das mais diversas que dificultam a sobrevivência das pessoas. Mas, que também podem surgir das questões ambientais, como quebra de safras ou a falta de água.

\section{REFERÊNCIAS}

AKATU. O dia "D” do consumo. São Paulo: Instituto Akatu, 2008.

ARIDA, P.. A história do pensamento econômico como teoria e retórica. São Paulo: Editora 34, 2003.

BAUMAN, Z.. Modernidade líquida. Rio de Janeiro: Jorge Zahar editor, 2001.

BECK, U.. Sociedade de risco: rumo a uma outra modernidade. São Paulo: Editora 34, 2010.

BRESSER PEREIRA, L. C.. Desenvolvimento e Crise no Brasil. São Paulo: Editora 34, 2003.

BRITO, R. P.; BRITO, L. A. L.. Vantagem Competitiva e sua Relação com o Desempenho-uma Abordagem Baseada em Valor. Revista de Administração Contemporânea, v.16, n.3, p.360-380, 2012. 
BROWN, L. R.. Eco-Economia: construindo uma economia para a terra. Salvador: UMA. 2003.

CASSIDY, J.. Como os mercados quebram: a lógica das catástrofes econômicas. Rio de Janeiro: Intrínseca, 2011.

COELHO, F. U.. Curso de direito comercial. 16 ed. São Paulo: Saraiva, 2012.

CRUVINEL, R.; PINTO, P.; GRANEMANN, S.. Mensuração econômica da emissão de CO2 da frota dos transportadores autônomos de cargas brasileiros. Journal of Transport Literature, v.6, n.1, 2012.

DA SILVA, M. E.. Consumo sustentável: a articulação de um constructo sob a perspectiva do desenvolvimento sustentável. Revista Eletrônica de Ciência Administrativa, v.11, n.2, 2012.

DOWBOR, L.. Producers, intermediaries and consumers: the price chain approach. 2013.

ELTZ, M. K. F.. Uma Abordagem da Análise Econômica do Direito para os Danos Ambientais Transfronteiriços. Economic Analysis of Law Review, v.3, n.1, p.40-56, 2012.

ENGELMAN, R.. Além do blablablá da sustentabilidade. Salvador: Uma Ed., 2013.

GONÇALVES, O. O.; RIBEIRO, M. M.. Incentivos Fiscais: uma perspectiva da Análise Econômica do Direito. Economic Analysis of Law Review, v.4, n.1, p.79-102, 2013.

HARRISON, R.. Pressure Groups, Campaigns and Consumers. London: Sage , 2005, p.55-67.

HAWKEN, P.; LOVINS, A. B.; LOVINS, L. H.. Capitalismo natural. São Paulo: Cultrix, 2002.

HENDERSON, H.. Construindo um mundo onde todos ganhem. São Paulo: Cultrix, 1996.

HENDERSON, H.. Além da globalização. São Paulo: Cultrix, 2003.

HENDERSON, H.. Transcendendo a economia. São Paulo: Cultrix, 1991.

KELLER, K. L.; KOTLER, P.. Administração de marketing. São Paulo: Pearson Prentice Hall, 2006.

LEITE, J. R. M.; SILVA, L. J. A.. Juridicidade do Dano Ambiental: gestão da zona costeira e aspectos da exploração do pré-sal pelo Brasil. Sequência, Florianópolis, n.65, p.305-328, 2012.

MATOS, A. et al. Limites e possibilidades da economia ambiental. Revista Egitania Sciencia. v.8, n.1, p. 39-60, 2011.

MORIN, E.. A Via Para o Futuro da Humanidade. São Paulo: Bertrand Brasil, 2013.

NUNES, L. H.; VASCONCELOS, I. F. G.; JAUSSAUD, J.. Expatriação de executivos: Coleção debate em administração. São Paulo: Thomson Learning, 2008.

OECD.Organization for Economic Co-operation and Development. Moving Freight with Better Trucks: Improving Safety, Productivity and Sustainability. OECD Publishing, 2011.

PERELMAN, C.; OLBRECHTS-TYTECA, L.. Tratado da argumentação: a nova retórica. São Paulo: Martins Fontes, 2005.

RAMALHO, A. M. C.. A Tessitura da Responsabilidade Social Corporativa: Desafios para o Consumo e Desenvolvimento Sustentável. Tese (Doutorado em Recursos Naturais) - Universidade Federal de Campina Grande, Campina Grande, 2011.

ROBINSON, J.. Squaring the circle? some thoughts on the idea of sustainable development. Ecological Economics, v.48, n.4, p. 369-384, 2004.

SUKHDEV Pavan. Transformando a Corporação em um Vetor de Sustentabilidade. Salvador: Uma Ed., 2013.

SCHEIN, E. H.. Cultura organizacional e liderança. São Paulo: Atlas, 2009.

TEIXEIRA, F. M. P.; TOTINI, M. E.. História econômica e administrativa do Brasil. São Paulo: Ática, 1989 . 